\title{
A Comprehensive Pediatric Asthma Management Program Reduces Emergency Department Visits and Hospitalizations
}

\author{
Khalid H. Safi, MD, Karla J. Stoermer-Grossman, RN, Kelley M. Kidwell, PhD, Julie M. Sturza, MPH, \\ Ixsy A. Ramirez, MD,' Thomas G. Saba, MD,' Marc B. Hershenson, MD, \\ Toby C. Lewis, MD, MPH, and Manuel Arteta, MD ${ }^{1}$
}

We evaluated the impact of a comprehensive pediatric asthma management program (the Children's Asthma Wellness Program, CAWP) on the frequency of emergency department (ED) visits and hospital admissions. The CAWP generally consisted of 4 clinic sessions over a 1-year period, but some patients attended fewer clinic sessions, and some required additional clinic sessions due to incomplete asthma control. Patients were evaluated and treated by pediatric pulmonologists, nurse asthma care coordinator/educator, and social worker. We retrospectively reviewed program results over an 8-year period (2005-2013). We compared ED visits and hospital admissions before and after participation in the CAWP. There were 254 children referred to the CAWP; 172 children were enrolled. Fifty-four children (31\%) received $>6$ sessions due to incomplete asthma control. On average, children requiring additional clinic sessions were older and more likely to be African American, hold Medicaid insurance, and have severe asthma. We obtained a minimum of 1-year preprogram and 1-year postprogram administrative data for 86 children (50\%). Using each participating child as his/her own control, we found that taking part in the program decreased the risk of ED visits to 0.26 times the preprogram rate $(P<0.0001)$ and decreased the risk of hospitalizations to 0.13 times the preprogram rate $(P<0.0001)$. A 1 -year comprehensive asthma care program emphasizing close follow-up and asthma education was effective in reducing healthcare utilization by reducing rates of ED visits and hospitalizations. However, a significant fraction of children required additional clinic visits due to gain complete asthma control.

\section{Introduction}

A STHMA IS a common disease, with an overall prevalence of $6 \%-7 \%$ in the general population. ${ }^{1}$ Furthermore, $32 \%$ of preschool children in the United States and Europe report recurrent asthma-like symptoms. ${ }^{2}$ It is estimated that $\sim 300$ million people in the world currently have asthma, and asthma prevalence has been increasing in the past few decades. ${ }^{3,4}$

In addition to causing significant morbidity affecting the quality of life of those with the condition, asthma imposes a significant burden on healthcare systems. ${ }^{5,6}$ The economic costs associated with asthma are estimated to rank among the highest of all chronic diseases. To decrease the asthma burden on patients, families, and health systems, many comprehensive asthma management programs have been established nationwide. These programs improved patients' asthma control and reduced healthcare utilization. ${ }^{7-10}$
The Children's Asthma Wellness Program (CAWP) is a comprehensive asthma care program that operates within the University of Michigan C.S. Mott Children's Hospital Department of Pediatrics and Communicable Diseases Division of Pediatric Pulmonology. The program was established in November 2005 to provide intensive individualized asthma management services for children with high risk or impairment and their caregivers, with emphasis on treatment compliance. The program targets children 3 years and older with persistent asthma who are at increased risk for repeated emergency department (ED) visits and hospitalization. CAWP services include clinical assessment, asthma education, facilitation of support services, and clinical monitoring of outcomes. The CAWP team is composed of pediatric pulmonologists, a half-time clinical nurse coordinator/educator, and a half-time social worker.

To assess the effectiveness of the program, we performed a retrospective study evaluating the impact of CAWP on ED

\footnotetext{
${ }^{1}$ Department of Pediatrics and Communicable Diseases, University of Michigan Medical School, Ann Arbor, Michigan.

${ }^{2}$ Department of Biostatistics, University of Michigan School of Public Health, Ann Arbor, Michigan.

${ }^{3}$ University of Michigan Center for Human Growth and Development, Ann Arbor, Michigan.
} 
Table 1. Characteristics of Patients Referred But Not Enrolled in the Children's Asthma Wellness Program and Patients Enrolled in the Children's Asthma Wellness Program

\begin{tabular}{|c|c|c|c|c|c|}
\hline \multirow[b]{2}{*}{ Characteristic } & \multicolumn{2}{|c|}{ Referred but unenrolled $(\mathrm{n}=82)$} & \multicolumn{2}{|c|}{ Enrolled $(\mathrm{n}=172)$} & \multirow[b]{2}{*}{$\mathrm{P}$ value } \\
\hline & Mean (SD) & Median (range) & Mean (SD) & Median (range) & \\
\hline Age (years) & $8.4(4.2)$ & $7.2(3.1-17.9)$ & $7.4(3.6)$ & $6.6(3.0-17.5)$ & 0.08 \\
\hline \multirow[t]{2}{*}{ Median income (thousands) } & $54.0(12.1)$ & $51.2(32.8-90.0)$ & $57.0(13.4)$ & $53.3(30.1-90.0)$ & 0.07 \\
\hline & $N$ & $\%$ & $N$ & $\%$ & \\
\hline Race $^{\mathrm{a}}$ & & & & & 0.69 \\
\hline White & 25 & 41.7 & 72 & 41.9 & \\
\hline Black & 30 & 50.0 & 79 & 45.9 & \\
\hline Other & 5 & 8.3 & 21 & 12.2 & \\
\hline Gender & & & & & 1.00 \\
\hline Female & 31 & 37.8 & 65 & 37.8 & \\
\hline Male & 51 & 62.2 & 107 & 62.2 & \\
\hline Insurance type $\mathrm{e}^{\mathrm{b}}$ & & & & & 1.0 \\
\hline Commercial & 23 & 39.7 & 66 & 39.5 & \\
\hline Medicaid & 35 & 60.3 & 101 & 60.5 & \\
\hline \multicolumn{6}{|l|}{ Asthma severity } \\
\hline Nonsevere & & & 65 & 37.8 & \\
\hline Severe & & & 107 & 62.2 & \\
\hline
\end{tabular}

${ }^{\text {a}}$ Does not include 22 unenrolled patients with missing race data.

${ }^{\mathrm{b}}$ Does not include 24 unenrolled patients and 5 enrolled patients with missing insurance data.

and inpatient services among CAWP participants with at least 1 year of available data both before and after the program. We compared annual ED visits and hospital utilization before enrollment in the CAWP to those after completion of the program.

\section{Materials and Methods}

We retrospectively reviewed program results over a 9-year period (November 2005-October 2013). The CAWP enrolls patients referred from primary care providers, ED physicians, or inpatient pediatric teams. Criteria for referral to the CAWP were the following: (1) age 36 months-18 years at the time of referral and (2) one or more recent ED visits or hospital admissions due to acute asthma symptoms. Patients for whom symptoms were explained by diagnoses other than asthma, such as recurrent aspiration or airway malacia, were excluded. This study was approved by the University of Michigan Medical School Institutional Review Board.

The CAWP was designed to provide comprehensive asthma care and case management that includes clinical assessment of baseline asthma severity and degree of control at the time of enrollment; development of an asthma action plan; face-to-face intensive asthma education; facilitation of support services, including referral for an home environmental assessment; clinical monitoring of outcomes; and close follow-up in the CAWP clinic. The CAWP team is composed of pediatric pulmonologists, half-time clinical nurse coordinator ( 0.5 full-time equivalent), and a part-time social worker ( 0.2 full-time equivalent). It is distinct from the regular general pediatric pulmonary clinic in the following ways: (1) return visits offered every 1-3 months for follow-up care (vs. semiannual visits for the general pediatric pulmonary clinic); (2) longer visit times, allowing comprehensive asthma education ( $40 \mathrm{~min}$ for return visits vs. $20 \mathrm{~min}$ ); (3) education by a single certified asthma educator, emphasizing self-management skills and proper technique of medication delivery devices; (4) pharmacy review to monitor adherence; (5) additional social work services, including appointment reminder calls, advance planning for transportation, and other resources to facilitate access to care (vs. as-needed services); (6) referral to appropriate community-based resources, including home environmental assessments; (7) multidisciplinary monthly meetings to optimize the care of complex patients; and (8) dedicated case management, allowing comprehensive coordination of care with primary care providers, visiting nurses, ED staff, and inpatient care providers.

Education included patient and family knowledge of basic asthma pathophysiology and medications; increasing self-

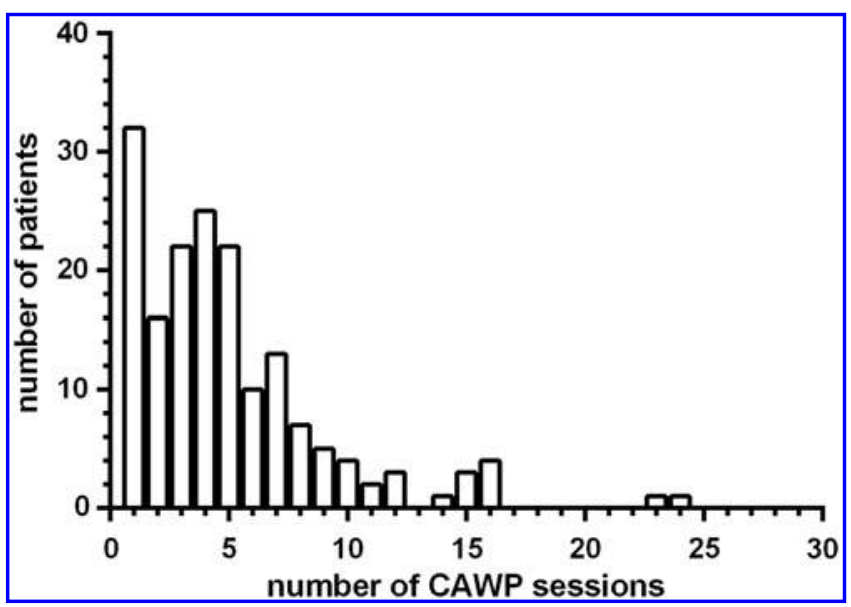

FIG. 1. Histogram showing the number of the Children's Asthma Wellness Program (CAWP) outpatient clinic sessions per patient $(n=172)$. 
Table 2. Characteristics of All the Children's Asthma Wellness Program Patients $(N=172)$ with $<6$ Clinic Sessions and Patients with >6 Clinic Sessions

\begin{tabular}{|c|c|c|c|c|c|}
\hline \multirow[b]{2}{*}{ Characteristic } & \multicolumn{2}{|c|}{$<6$ sessions in program $(\mathrm{n}=118)$} & \multicolumn{2}{|c|}{$\geq 6$ sessions in program $(\mathrm{n}=54)$} & \multirow[b]{2}{*}{$\mathrm{P}$ value } \\
\hline & Mean $(S D)$ & Median (range) & Mean $(S D)$ & Median (range) & \\
\hline Age (years) & $7.0(3.4)$ & $6.1(3.0-17.5)$ & $8.3(3.8)$ & $7.3(3.2-16.3)$ & 0.04 \\
\hline \multirow[t]{2}{*}{ Median income (thousands) } & $57.9(13.2)$ & $55.9(30.1-90.0)$ & $55.3(13.9)$ & $51.2(32.8-90.0)$ & 0.14 \\
\hline & $N$ & $\%$ & $N$ & $\%$ & \\
\hline Gender & & & & & 0.89 \\
\hline Female & 45 & 38.1 & 20 & 37.0 & \\
\hline Male & 73 & 61.9 & 34 & 63.0 & \\
\hline Race & & & & & 0.03 \\
\hline White & 57 & 48.3 & 15 & 27.8 & \\
\hline Black & 47 & 39.8 & 32 & 59.3 & \\
\hline Other & 14 & 11.9 & 7 & 13.0 & \\
\hline Insurance & & & & & 0.01 \\
\hline Commercial & 53 & 46.1 & 13 & 25.0 & \\
\hline Medicaid & 62 & 53.9 & 39 & 75.0 & \\
\hline Severity level & & & & & 0.03 \\
\hline Nonsevere & 51 & 43.2 & 14 & 25.9 & \\
\hline Severe & 67 & 56.8 & 40 & 74.1 & \\
\hline
\end{tabular}

management skills, including proper technique of medication delivery devices and peak flow monitoring as appropriate; understanding the asthma management/action plan; reducing the level of allergen exposure; when to contact healthcare providers; and providing a disease care skill set for the young patient to sustain throughout his/her lifetime. The social worker assisted families with insurance, pharmacy, transportation, school, and utility issues, which could hinder the delivery of asthma care. Access to medical support was available by phone $24 \mathrm{~h}$ a day and was provided by the CAWP team along with other staff nurses and on-call pediatric pulmonologists.

Most patients attended the clinic for 4 quarterly sessions, but some attended fewer clinic sessions, some were seen more frequently to assure asthma control, and some were retained in the clinic due to incomplete control. The criteria for discharge from the CAWP were no oral steroid treatment, ED visits, or hospitalization for 3 months; asthma control test score $>19$; family and patient satisfaction with asthma control; and their ability to manage asthma. After discharge, patients returned either to their primary care or previous subspecialty provider (allergy or pediatric pulmo- nary). Children capable of performing a forced expiratory maneuver underwent spirometry during their CAWP clinic sessions. Patients with severe asthma were identified using the NHLBI guidelines. ${ }^{11}$

Two hundred fifty-four patients were referred to the CAWP clinic. Eighty-two patients declined enrollment in the CAWP, leaving 172 children who were enrolled in the intervention. We compared demographics between those who enrolled in the program and those who did not using chi-square and Wilcoxon rank-sum tests. We also compared the demographic characteristics of subjects requiring $\leq 5$ versus $\geq 6$ CAWP clinic sessions.

Pre- and postprogram information on ED visits and hospitalizations at the University of Michigan C.S. Mott Children's Hospital was available for 105 patients from the electronic medical record. Of these, 86 had at least 1 year of both pre- and postprogram information available for analysis. To compare ED visits and inpatient hospitalizations during the periods before, during, and after the CAWP clinic sessions, we used 2 general statistical methods. First, we compared the raw number of ED visits, hospitalizations, and hospitalization days during the pre- and postprogram periods

Table 3. Effect of Period (Preprogram, During Program, and Postprogram) on Emergency Department Visits, Hospitalizations, and Hospitalization Days (for Patients Who Had At Least One Year Each of Pre- and Postprogram Data, $N=86$ )

\begin{tabular}{|c|c|c|c|c|c|c|}
\hline \multirow[b]{2}{*}{ Characteristic } & \multicolumn{2}{|c|}{ Preprogram } & \multicolumn{2}{|c|}{ During program } & \multicolumn{2}{|c|}{ Postprogram } \\
\hline & Mean (SD) & Median (range) & Mean $(S D)$ & Median (range) & Mean (SD) & Median (range) \\
\hline Dura & $2.13(0.60)$ & $2(1.63-6$ & $1.66(0.91)$ & $1.37(0.35-4$. & $2.00(0.31)$ & $2(1.01-3$ \\
\hline ED visits $(n)$ & $1.13(1.65)$ & $1(0-9)$ & $0.47(0.78)$ & $0(0-3)$ & $0.27(0.56)^{\mathrm{a}}$ & $0(0-3)$ \\
\hline Hospitalizations $(n)$ & $1.20(1.29)$ & $1(0-10)$ & $0.27(0.69)$ & $0(0-4)$ & $0.16(0.48)^{\mathrm{a}}$ & $0(0-3)$ \\
\hline Hospitalization days (total) & $3.69(4.25)$ & $3(0-22)$ & $0.86(2.51)$ & $0(0-15)$ & $0.48(1.64)^{\mathrm{a}}$ & $0(0-11)$ \\
\hline Length of stay (days) & $3.11(2.01)$ & $2(1-10)$ & $3.52(1.20)$ & $4(2-6)$ & $3.00(1.69)$ & $2(1-8)$ \\
\hline
\end{tabular}

${ }^{a}$ Different from preprogram, $P<0.0001$, Wilcoxon matched-pairs signed-rank test.

$\mathrm{ED}$, emergency department. 
using the Wilcoxon matched-pairs signed-rank test. Second, we compared the rates of ED visits and hospitalization per year using negative binomial models for overdispersed data controlling for patient age at enrollment, gender, self-reported race, insurance type, family median income based on residential ZIP code, and severity of disease. We accounted for the correlation in the rate of ED visits and hospitalizations for each subject between periods using a mixed model with a random intercept. Since the program enrollment period differed for individuals, we included an offset in the model as the number of years the person was followed in each period.

\section{Results}

The characteristics of the group of patients who were referred but not enrolled in the program (unenrolled group, $n=82$ ) and the group of patients enrolled in the CAWP (intervention group, $n=172$ ) did not significantly differ in terms of age, gender, and median income (Table 1). There was significant amount of missing data for race (control group) and insurance type (both groups). When the bias for the missing data in the control group was corrected by eliminating patients with missing information, there was no statistically significant difference in race $(P=0.54)$ or insurance type $(P=0.86)$ between groups. There was no difference in age, median income, or gender between children with and without missing data (not shown).

One hundred seventy-two children were enrolled in the CAWP during the 8-year evaluation period. One hundred eighteen children $(68 \%)$ received $<6$ CAWP clinic sessions, and $54(31 \%)$ received $>6$ sessions (Fig. 1). The latter patients were significantly different with regard to age $(P=0.039$, Table 2$)$, race $(P=0.033)$, insurance type $(P=0.010)$, and asthma severity $(P=0.030)$.

One hundred five children had both pre- and postprogram health utilization information. For these children, the number of clinic sessions in the program ranged from 1 to 16 , with $83(79 \%)$ participants having $<6$ sessions (median, 4 sessions). Twenty-two (21\%) patients required $\geq 6 \mathrm{CAWP}$ sessions.

Of these, 86 children ( $49 \%$ of the 172 enrolled children) had pre- and postprogram periods of at least 1 year. There was considerable heterogeneity in duration in the program and length of observation periods before and after the program. The number of years in each period ranged from 1.61 to 6.74 years for the preprogram period, $0.35-4.56$ years during the program, and 1.01-3.63 years postprogram. The median length of both the pre- and postprogram periods was 2 years. With regard to outcomes, the total number of ED visits in the preprogram, during program, and postprogram periods was 97,40 , and 23 , respectively. The total number of hospitalizations in the preprogram, during program, and postprogram periods was 103,23 , and 14 , respectively. The average number of ED visits, hospitalizations, and total hospitalization days per patient significantly decreased from the preprogram period to the postprogram period (each $P<0.0001$, Table 3; Fig. 2). There was no change in the length of hospital stay between groups.

When we considered children with pre- and postprogram periods of at least 2 years $(n=79)$, we obtained nearly identical results, with significant reductions in ED visits, hospitalizations, and hospitalization days from the prepro-
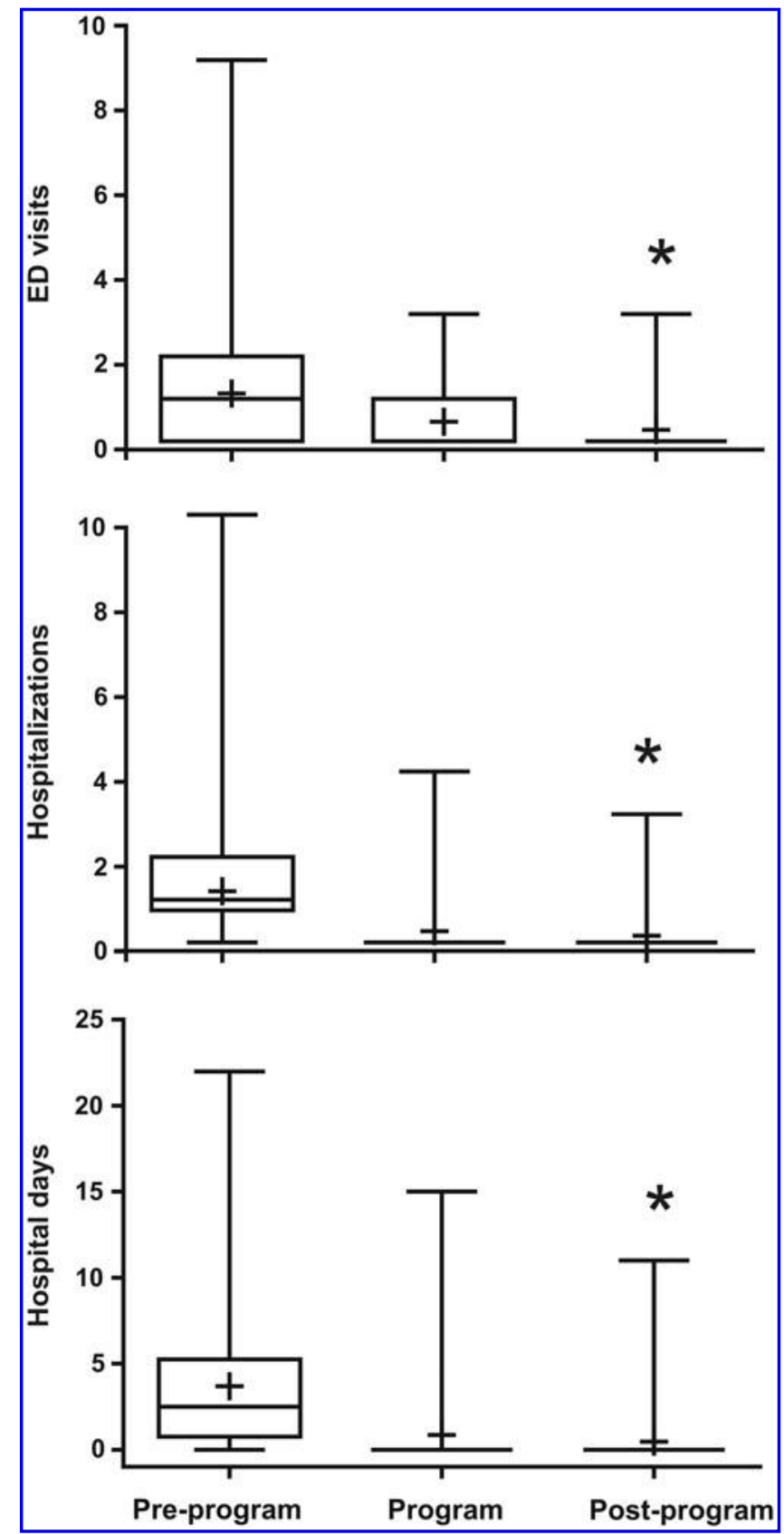

FIG. 2. Effect of period (preprogram, during program, and postprogram) on the number of emergency department (ED) visits (upper panel), inpatient hospitalizations (middle panel), and inpatient hospitalization days (lower panel). These data represent patients who had at least 1 year each of pre- and postprogram data $(n=86)$. Box shows median, 25 th, and 75 th percentiles; whiskers show minimum and maximum; + represents mean. ${ }^{*} P<0.0001$, Wilcoxon signed-rank test.

gram period to the postprogram period (Table 4). Thus, participation in the CAWP produced durable reductions in healthcare utilization.

We examined the influence of home environmental assessments on health outcomes. Of the 86 patients followed for a minimum of 1 year before and after program enrollment, 44 had home environmental assessments by a visiting nurse. For those subjects who accepted a home visit, the median number of visits was 3 (range, 0-32). Families 
Table 4. Effect of Period (Preprogram, During Program, and Postprogram) on Emergency Department Visits, Hospitalizations, and Hospitalization Days (for Patients Who Had At Least Two Years Each of Pre- ANd Postprogram Data, $N=79$ )

\begin{tabular}{lllllllll}
\hline & \multicolumn{2}{c}{ Preprogram } & & \multicolumn{2}{c}{ During program } & & \multicolumn{2}{c}{ Postprogram } \\
\cline { 2 - 3 } \cline { 7 - 8 } Characteristic & Mean $(S D)$ & Median (range) & & Mean $(S D)$ & Median $($ range) & & Mean $(S D)$ & Median (range) \\
\hline Duration (years) & $2.04(0.17)$ & $2(2-3.79)$ & & $1.76(0.88)$ & $1.43(0.51-4.56)$ & & $2.03(0.17)$ & $2(2-3.43)$ \\
ED visits $(n)$ & $0.99(1.45)$ & $0(0-6)$ & & $0.46(0.78)$ & $0(0-3)$ & & $0.23(0.55)^{\mathrm{a}}$ & $0(0-3)$ \\
Hospitalizations $(n)$ & $1.19(1.33)$ & $1(0-10)$ & & $0.29(0.72)$ & $0(0-4)$ & & $0.14(0.47)^{\mathrm{a}}$ & $0(0-3)$ \\
Hospitalization days (total) & $3.61(4.28)$ & $3(0-22)$ & & $0.94(2.60)$ & $0(0-15)$ & & $0.34(1.40)^{\mathrm{a}}$ & $0(0-11)$ \\
\hline
\end{tabular}

${ }^{a}$ Different from preprogram, $P<0.0001$, Wilcoxon matched-pairs signed-rank test.

accepting a home visit had significantly higher preprogram hospitalization days (Table $5, P=0.002$, unpaired $t$ test) and tended to have a higher number of preprogram hospitalizations $(P=0.058)$. In contrast, families accepting a home visit tended to have fewer hospitalizations and hospitalization days, although these differences did not reach statistical significance.

We also compared the rates of ED visits and hospitalization per year using negative binomial models controlling for patient age at enrollment, gender, self-reported race, insurance type, family median income based on ZIP code, and severity of disease. Patients with at least 1 year of preand postprogram data were included in this analysis. There was a borderline inverse association between increasing age and the total rate of ED visits before, during, and after the CAWP $[P=0.06$, relative risk $0.92,95 \%$ confidence interval (CI) $0.85-1.00]$. Race $(P=0.96)$, insurance type $(P=0.37)$, gender $(P=0.59)$, severity level $(P=0.45)$, and median family income $(P=0.80)$ were not significantly associated with the rate of ED visits. Controlling for these covariates, the period (preprogram, during program, or postprogram) was significantly associated with the rate of ED visits (Table 6). The risk of ED visits in the postprogram period significantly decreased to 0.26 times the preprogram period risk (95\% CI $0.14-0.45, P<0.0001)$. The risk of ED visits postprogram was also significantly decreased compared to the in-program risk (risk of ED visits postprogram was 0.41

TABle 5. EMERgency Department Visits, Hospitalizations, and Hospitalization Days Grouped by OCCURRENCE OF Visiting Nurse ASSESSMENT (For Patients Who Had at Least One Year Each of Pre- ANd Postprogram Data, $N=86$ )

\begin{tabular}{lccl}
\hline & Yes & No & P value \\
\hline $\begin{array}{l}\text { Nursing home visit } \\
\quad \text { Number }\end{array}$ & 44 & 42 & \\
$\quad$ Mean (SD) & $6.27(7.99)$ & 0 & \\
$\quad$ Median (range) & $3(0-32)$ & 0 & \\
ED visits ( $n$ ) & & & \\
$\quad$ Preprogram, mean (SD) & $0.95(1.78)$ & $1.31(1.51)$ & 0.32 \\
$\quad$ Postprogram, mean (SD) & $0.25(0.53)$ & $0.29(0.60)$ & 0.77 \\
Hospitalizations (n) & & & \\
$\quad$ Preprogram, mean (SD) & $1.45(1.58)$ & $0.93(0.84)$ & 0.058 \\
$\quad$ Postprogram, mean (SD) & $0.11(0.32)$ & $0.21(0.61)$ & 0.33 \\
Hospitalization days (total) & & & \\
$\quad$ Preprogram, mean (SD) & $5.07(5.09)$ & $2.34(2.63)$ & 0.003 \\
$\quad$ Postprogram, mean (SD) & $0.26(0.79)$ & $0.73(2.21)$ & 0.19 \\
\hline
\end{tabular}

times the in-program rate, 95\% CI $0.22-0.77, P=0.007$ ). Results also showed a suggestive decrease in ED visit rate from the preprogram period to the in-program period (relative risk 0.62 ; $95 \% \mathrm{CI} 0.37-1.04, P=0.07$ ).

For inpatient hospitalizations, severity level $(P=0.32)$, race $(P=0.38)$, insurance type $(P=0.63)$, gender $(P=0.11)$, age $(P=0.43)$, and median family income $(P=0.26)$ were not significantly associated with the rate of inpatient hospitalizations. Controlling for these covariates, the period (preprogram, during program, or postprogram) was significantly associated with the rate of inpatient hospitalizations $(P<0.0001)$.

The risk of inpatient hospitalization postprogram significantly decreased to 0.13 times the preprogram rate $(95 \% \mathrm{CI}$ $0.07-0.25, P<0.0001)$. There was no difference in the risk of inpatient hospitalizations postprogram compared to that during the program (relative risk 0.61, 95\% CI 0.29-1.28, $P=0.19)$. The risk of inpatient hospitalization during the program decreased to 0.22 times the preprogram risk $(95 \%$ CI $0.13-0.38, P<0.0001)$.

\section{Discussion}

The goal of the University of Michigan C.S. Mott Children's Hospital CAWP was to provide comprehensive asthma care and education to reduce the burden of asthma on patients and families and to prevent the need for emergency and inpatient health services. The objective of this study was to evaluate the effectiveness of CAWP in achieving this goal. We found that, using each participating child as his/her own control, taking part in the program significantly decreased the risk of ED visits (postprogram risk decreased to 0.26 of preprogram risk, $P<0.0001$ ) and hospitalizations (postprogram risk decreased to 0.13 of preprogram risk, $P<0.0001)$. Taken together, these data suggest that the CAWP, which emphasized case management, education, and additional social work services, was effective in reducing healthcare utilization of children with chronic asthma.

Previous studies have examined the outcomes of comprehensive pediatric asthma programs on hospital utilization. A prospective randomized study of a comprehensive innercity asthma program in New York City, similar to our own, showed that patients in the study group had fewer ED visits (after 1 year) and hospitalizations (after 2 years) compared to those in a control group. ${ }^{8}$ In this program, study patients participated in three 1-h sessions 2 weeks apart, followed by close standardized management by a pediatric allergist or 1 of 3 pediatric nurse practitioners, including availability of a provider on a 24-h basis. Patients received allergy testing and instructions on environmental control measures. The authors 
Table 6. Effect of Period (Preprogram, During Program, and Postprogram) on Rates of Emergency Department Visits and Hospitalizations (for Patients Who Had At Least One Year of Both Pre- AND Postprogram Data, $N=86$ )

\begin{tabular}{|c|c|c|c|}
\hline & \multicolumn{3}{|c|}{ Patients in program $(\mathrm{n}=86)$} \\
\hline & $\begin{array}{c}\text { Preprogram } \\
\text { N (\%) }\end{array}$ & $\begin{array}{c}\text { During program } \\
\text { N }(\%)\end{array}$ & $\begin{array}{l}\text { Postprogram } \\
\text { N (\%) }\end{array}$ \\
\hline \multicolumn{4}{|l|}{ ED visits } \\
\hline None & $42(48.8)$ & $57(66.3)$ & $66(76.7)$ \\
\hline Any & $44(51.2)$ & $29(33.7)$ & $19(22.1)^{\mathrm{a}}$ \\
\hline Rate for all children, mean (SD) & $0.51(0.71)$ & $0.34(0.60)$ & $0.14(0.28)^{\mathrm{b}, \mathrm{c}}$ \\
\hline Rate for all children, median (range) & $0.30(0.00-3.00)$ & $0.00(0.00-3.62)$ & $0.00(0.00-1.00)$ \\
\hline Rate for those with any visits per year, mean (SD) & $1.00(0.70)$ & $0.99(0.64)$ & $0.63(0.23)$ \\
\hline Rate for those with any visits per year, median (range) & $0.55(0.30-3.00)$ & $0.88(0.25-3.62)$ & $0.50(0.28-1.0)$ \\
\hline \multicolumn{4}{|l|}{ Inpatient hospitalizations } \\
\hline None & $21(24.4)$ & $71(82.6)$ & $75(87.2)$ \\
\hline Any & $65(75.6)$ & $15(17.4)$ & $11(12.8)$ \\
\hline Rate for all children, mean (SD) & $0.58(0.64)$ & $0.14(0.33)^{\mathrm{b}}$ & $0.08(0.23)^{\mathrm{b}}$ \\
\hline Rate for all children, median (range) & $0.50(0.00-5.00)$ & $0.00(0.00-1.66)$ & $0.00(0.00-1.22)$ \\
\hline Rate for those with any & $0.77(0.62)$ & $0.78(0.37)$ & $0.62(0.27)$ \\
\hline hospitalizations per year, mean (SD) & & & \\
\hline $\begin{array}{l}\text { Rate for those with any } \\
\text { hospitalizations per year, median (range) }\end{array}$ & $0.50(0.24-5.00)$ & $0.73(0.25-1.66)$ & $0.50(0.28-1.22)$ \\
\hline
\end{tabular}

${ }^{\mathrm{a}}$ One child missing postprogram ED visit data.

${ }^{\mathrm{b}}$ Different from preprogram rate, $P<0.0001$.

${ }^{\mathrm{c}}$ Different from during program rate, $P=0.007$.

attributed the success of their program to frequent follow-up clinic sessions, identification of allergies and exposure reduction measures, and availability of nighttime support, which allowed initiation of steroids early in exacerbations. They attributed the delay in reaching maximal results to the time needed for patients and caregivers to gain confidence in telephone management, as well as the time needed for the multiple interventions to result in optimal effect. We observed a similar phenomenon, with some subjects continuing to seek care in the ED instead of over the telephone.

In contrast to our somewhat traditional, hospital-based program, other models of asthma management have focused on telephone-, community-, or school-based programs. A largescale intensive Telephonic Care Management program carried out primarily by registered nurses and respiratory therapists significantly reduced the percentage of patients requiring inpatient admission or emergency room care. ${ }^{10}$ More recently, a community-based program was also shown to improve healthcare utilization in children with asthma. This program, which emphasized nurse case management including home visits for asthma education, environmental assessment, and remediation, ${ }^{9}$ demonstrated a significant reduction in asthma ED visits, hospitalizations, limitation of physical activity, missed school, and parent/guardian missed work at 6 and 12 months of follow-up. Finally, because children attend school daily, school-based interventions for children with persistent asthma could provide effective disease management for asthmatic children. Enrollment in a special school for children with chronic diseases, including asthma, reduced hospitalizations, ED visits, and follow-up clinic sessions for asthma. ${ }^{12}$

We speculate that nonphysician aspects of the programthe social worker, who addressed issues with access to healthcare before problems arose; the dedicated nurse coordinator/educator, who facilitated communication and adherence to the medical plan; and the visiting nurse, who performed an environmental assessment and asthma education-were the most important factors in the improved outcomes we observed. Interestingly, families who accepted home visits were hospitalized a greater number of days preprogram and tended to be hospitalized fewer days postprogram. All asthma management programs share asthma education as an integrated essential component. A metaanalysis showed that pediatric asthma education reduces hospitalizations, ED visits, urgent physician visits for asthma, and other measures of asthma control. ${ }^{13}$ The analysis also suggested that interventions that involve more sessions and provide more opportunities for interaction between educators and children or caregivers, as in the CAWP, may be more effective. However, we found that patients with only 1 or 2 CAWP sessions-nearly one-quarter of the patients-still benefitted from the program. In contrast, due to incomplete asthma control, 54 of 172 patients enrolled in the CAWP required $\geq 6$ clinic sessions, and even then, some of these patients could not be discharged from the program. Patients with $\geq 6$ CAWP clinic sessions were more likely to be African American, hold Medicaid rather than commercial insurance, and have severe asthma compared to those with $<6$ sessions. These data suggest that, while our intervention program was effective in reducing ED visits and hospitalizations, a different care model, which includes ongoing care (not just education), is needed for this important subgroup of severe asthma patients.

We did not directly measure the medical expenses saved by the CAWP. However, assuming a charge of $\$ 9,100$ for each hospital admission with asthma as a principal diagnosis, ${ }^{14}$ we calculate that the reduction in hospital admissions alone saved $\$ 809,000$ over the duration of the program. This is about twice the cost of the CAWP staff, which consisted of a part-time nurse coordinator and social worker. In the future, programs, such as ours, will become increasingly important as insurers move to payment per person (capitated) rather than fee for service-based systems. 
While the CAWP reduced ED visits and hospitalizations, there are areas in which our program could be significantly improved. First, a substantial proportion of children referred to the CAWP did not enroll in the program. The reasons why these families declined participation are unclear. There was no statistically significant difference in race or insurance type between this group of children and the CAWP enrollees. It is possible that the cohort of patients and families who enrolled in the CAWP was more committed to treating their asthma, a factor that likely contributed to the success of our program. Second, despite reminder phone calls and advance planning for transportation, many patients failed to appear or canceled their scheduled clinic visits. During the 2-year period beginning September 1, 2010, the no-show rate was $35 \%$. To address this issue, we are considering additional incentives, such as parking passes or gift cards, to improve clinic attendance. Third, as noted above, many patients remained in the CAWP for long after the standard 1-year required due to incomplete asthma control. The majority of patients with difficult-to-control asthma are nonadherent with their asthma medication, ${ }^{15}$ although the reasons for this can be complex. Therefore, future efforts aimed at increasing patient enrollment, clinic show rate, and medication adherence could improve patient outcomes.

Interpretation of this project's findings should be considered in the context of several limitations. First, missing data in the unenrolled group was $\sim 25 \%$ for race and insurance type, limiting interpretation of these factors. Second, the level of intervention varied between different patients enrolled in the CAWP. Depending on asthma severity and control, patients were seen in the clinic at different intervals, so that the same number of sessions may not represent the same duration of intervention. Third, while patients with 2-year pre- and postprogram data were monitored closely at the University of Michigan, it is conceivable that some families did not inform us about care at outside hospitals. Fourth, while we measured the major drivers of asthma healthcare expense (ED visits and hospitalizations), we did not examine the effects of the CAWP on other measures of asthma control, including pulmonary function, asthma control test scores, steroid use, or quality of life measures. While we monitored pulmonary function, asthma control test scores, and steroid use during CAWP sessions, these data were not collected before and after participation in the program.

In conclusion, results of this study support the existing evidence that comprehensive asthma management programs are effective in reducing rates of ED visits and hospital admission in children. Such programs reduce the burden of asthma on patients, their families, and healthcare providers.

\section{Acknowledgments}

This study was supported by the University of Michigan Medical School Department of Pediatrics and Communicable Diseases.

\section{Author Disclosure Statement}

No competing financial interests exist.

\section{References}

1. Moorman JE, Zahran H, Truman BI, Molla MT. Current asthma prevalence-United States, 2006-2008. MMWR Surveill Summ 2011; 60 Suppl:84-86.
2. Bisgaard H, Szefler S. Prevalence of asthma-like symptoms in young children. Pediatr Pulmonol 2007; 42:723-728.

3. Mannino DM, Homa DM, Akinbami LJ, Moorman JE, Gwynn C, Redd SC. Surveillance for asthma-United States, 1980-1999. MMWR Surveill Summ 2002; 51:1-13.

4. Moorman JE, Rudd RA, Johnson CA, King M, Minor P, Bailey C, Scalia MR, Akinbami LJ. National surveillance for asthma-United States, 1980-2004. MMWR Surveill Summ 2007; 56:1-54.

5. Fuhlbrigge AL, Adams RJ, Guilbert TW, Grant E, Lozano P, Janson SL, Martinez F, Weiss KB, Weiss ST. The burden of asthma in the United States. Am J Respir Crit Care Med 2002; 166:1044-1049.

6. Weiss KB, Sullivan SD. The health economics of asthma and rhinitis. I. Assessing the economic impact. J Allergy Clin Immunol 2001; 107:3-8.

7. Robichaud P, Laberge AE, Allen M-F, Boutin Hln, Rossi C, Lajoie P, Boulet L-P. Evaluation of a program aimed at increasing referrals for asthma education of patients consulting at the emergency department for acute asthma. Chest 2004; 126:1495-1501.

8. Harish Z, Bregante AC, Morgan C, Fann CSJ, Callaghan CM, Witt MA, Levinson KA, Caspe WB. A comprehensive innercity asthma program reduces hospital and emergency room utilization. Ann Allergy Asthma Immunol 2001; 86:185-189.

9. Woods ER, Bhaumik U, Sommer SJ, Ziniel SI, Kessler AJ, Chan E, Wilkinson RB, Sesma MN, Burack AB, Klements EM, Queenin LM, Dickerson DU, Nethersole S. Community asthma initiative: evaluation of a quality improvement program for comprehensive asthma care. Pediatrics 2012; 129:465-472.

10. Georgiou A, Buchner DA, Ershoff DH, Blasko KM, Goodman LV, Feigin J. The impact of a large-scale population-based asthma management program on pediatric asthma patients and their caregivers. Ann Allergy Asthma Immunol 2003; 90:308-315.

11. National Asthma Education and Prevention Program Expert Panel Report 3. Guidelines for the diagnosis and management of asthma. Bethesda, MD: National Heart, Lung and Blood Institute, 2007.

12. Anderson ME, Freas MR, Wallace AS, Kempe A, Gelfand EW, Liu AH. Successful school-based intervention for inner-city children with persistent asthma. J Asthma 2004; 41:445-453.

13. Coffman JM, Cabana MD, Halpin HA, Yelin EH. Effects of asthma education on children's use of acute care services: a meta-analysis. Pediatrics 2008; 121:575-586.

14. Merrill CT, Stranges E, Steiner C. Hospital stays for asthma among children, 2006. HCUP Statistical Brief No. 58. Rockville, MD: Agency for Healthcare Research and Quality, 2008.

15. Murphy AC, Proeschal A, Brightling CE, Wardlaw AJ, Pavord I, Bradding P, Green RH. The relationship between clinical outcomes and medication adherence in difficult-tocontrol asthma. Thorax 2012; 67:751-753.

Address correspondence to: Manuel Arteta, MD Department of Pediatrics and Communicable Diseases University of Michigan Medical School Ann Arbor, MI 48109

E-mail: marteta@med.umich.edu

Received for publication July 16, 2015; accepted after revision December 7, 2015. 
This article has been cited by:

1. Cataletto Mary. 2016. Asthma 2016. Pediatric Allergy, Immunology, and Pulmonology 29:1, 1-1. [Citation] [Full Text HTML] [Full Text PDF] [Full Text PDF with Links] 